\title{
PELATIHAN DAN PENDAMPINGAN PEMBUATAN VIDEO MENGGUNAKAN KAMERA HANDHONE BAGI ANGGOTA GP ANSOR KABUPATEN TANGERANG
}

\author{
Dr Indiwan Seto Wahjuwibowo MSI \\ Dosen Ilmu Komunikasi Universiitas Multimedia Nusantara \\ E-Mail: indiwan@umn.ac.id
}

\begin{abstract}
ABSTRAK
Sebagai sebuah organisasi yang cukup besar Gerakan Pemuda ( GP ) Ansor merupakan ormas yang banyak melakukan kegiatan. Dan kegiatan ini perlu dipublikasikan ke tengah masyarakat. Tetapi seringkali kendalanya adalah organisasi itu tidak memiliki kemampuan sekaligus sumber daya yang memadai yang bisa mempublikasikan seluruh kegiatan organisasi secara cepat dan professional. GP Ansor banyak kegiatan khususnya di wilayah Kabupaten Tangerang tapi miskin publikasi, Pubikasi kurang mengenai sasaran karena keterbatasan SDM yang mengetahui bagaimana melakukan publikasi yang efektif. Maka dari itu, kami dosen UMN beserta sejumlah mahasiswa memberi pelatihan dan pendampingan kepada peserta dari GP Ansor membbuat video praktis memanfaatkan aplikasi android Videoshow dan Canva yang mudah digunakan. Metode yang dilakukan adalah dengan mengajarkan langsung bagaimana mencari aplikasi android yag sesuai untuk kepentingan publikasi, kemudian mengajari bagaimana cara mengambil gambar dan video yang baik menggunakan handphone, kemudian mengajari peserta mengedit hasil karya mereka dengan memasukan ilustrasi, efek dan music yang sesuai agar karya mmereka menarik untuk dilihat orang banyak. Terakhir memberi pendampingan dan kiat mempublikasikan karya video mereka ke media social seperti facebook, Instagram dan Youtube. Hasil dari pendampingan ini para peserta bisa mengoperasikan kamera handphone mereka untuk merekam video dan melakukan editing dan bisa mempublikasikan karya mereka di Youtube atau Instagram mereka. Secara sederhana pelatihan ini bisa menambah pemahaman dan keterampilan peserta dalam mempublikasikan karya video mereka sendiri dan di kemudian hari bisa mempublikasikan kegiatan GP Ansor Kabuoaten Tangerang secara professional dan menarik di media massa dan media social.
\end{abstract}

Keywords : GP Ansor, pelatihan videografi, publikasi menggunakan video, Video praktis

\section{PENDAHULUAN}

Sebagai sebuah organisasi yang cukup besar Gerakan Pemuda ( GP ) Ansor merupakan ormas yang banyak melakukan kegiatan. Dan kegiatan ini perlu dipublikasikan ke tengah masyarakat. Sejarah lahirnya GP Ansor tidak bisa dilepaskan dari sejarah panjang kelahiran dan gerakan NU itu sendiri. Tahun 1921 telah muncul ide untuk mendirikan organisasi pemuda secara intensif. Hal itu juga didorong oleh kondisi saat itu, di mana-mana muncul organisasi pemuda bersifat kedaerahan seperti, Jong Java, Jong Ambon, Jong Sumatra, Jong Minahasa, Jong Celebes dan masih banyak lagi yang lain.

Dibalik ide itu, muncul perbedaan pendapat antara kaum modernis dan tradisionalis. Disebabkan oleh perdebatan sekitar tahlil, talkin, taqlid, ijtihad, mazhab dan masalah furuiyah lainnya. Tahun 1924 KH. Abdul Wahab membentuk organisasi sendiri bernama Syubbanul Wathan (pemuda tanah air). Organisasi baru itu kemudian dipimpin oleh PROSIDING PKM-CSR $2019 \mid 168$ 
Abdullah Ubaid (Kawatan) sebagai Ketua dan Thohir Bakri (Peraban) sebagai Wakil Ketua dan Abdurrahim (Bubutan) selaku sekretaris.

Setelah Syubbanul Wathan dinilai mantap dan mulai banyak remaja yang ingin bergabung. Maka pengurus membuat seksi khusus mengurus mereka yang lebih mengarah kepada kepanduan dengan sebutan "ahlul wathan". Sesuai kecendrungan pemuda saat itu pada aktivitas kepanduan sebagaimana organisasi pemuda lainnya. Setelah NU berdiri (31 Januari 1926), aktivitas organisasi pemuda pendukung KH. Abdul Wahab (pendukung NU) agak mundur. Karena beberapa tokoh puncaknya terlibat kegiatan NU. Meskipun demikian, tidak secara langsung Syubbanul Wathan menjadi bagian (onderbouw) dari organisasi NU.

Atas inisiatif Abdullah Ubaid, akhirnya pada tahun 1931 terbentuklah Persatuan Pemuda Nahdlatul Ulama (PPNU). Kemudian tanggal 14 Desember 1932, PPNU berubah nama menjadi Pemuda Nahdlatul Ulama (PNU). Pada tahun 1934 berubah lagi menjadi Ansor Nahdlatul Oelama (ANO). Meski ANO sudah diakui sebagai bagian dari NU, namun secara formal organisasi belum tercantum dalam struktur NU, hubungannya masih hubungan personal.

Ansor dilahirkan dari rahim Nahdlatul Ulama (NU) karena tuntutan kebutuhan alamiah Jam'iyyah. Berawal dari perbedaan antara tokoh tradisional dan tokoh modernis yang muncul di tubuh Nahdlatul Wathan, organisasi keagamaan yang bergerak di bidang pendidikan Islam, pembinaan mubaligh, dan pembinaan kader. $\mathrm{KH}$ Abdul Wahab Hasbullah, tokoh tradisional dan $\mathrm{KH}$ Mas Mansyur yang berhaluan modernis, akhirnya menempuh arus gerakan yang berbeda justru saat

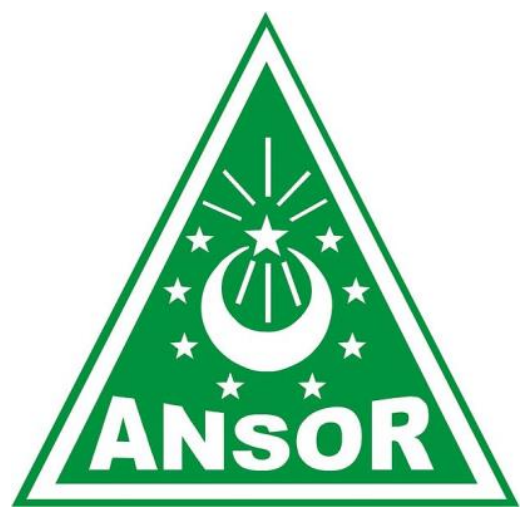

kepemudaan Islam.

Dua tahun setelah perpecahan itu, pada 1924 para pemuda yang mendukung $\mathrm{KH}$ Abdul Wahab,yang kemudian menjadi pendiri NU membentuk wadah dengan nama Syubbanul Wathan (Pemuda Tanah Air). Organisasi inilah yang menjadi cikal bakal berdirinya Gerakan Pemuda Ansor setelah sebelumnya mengalami perubahan nama seperti Persatuan Pemuda NU (PPNU), Pemuda NU (PNU), dan Anshoru Nahdlatul Oelama (ANO).

Nama Ansor ini merupakan saran KH. Abdul Wahab (ulama besar sekaligus guru besar kaum muda saat itu), yang diambil dari nama kehormatan yang diberikan Nabi Muhammad SAW kepada penduduk Madinah yang telah berjasa dalam perjuangan membela dan menegakkan agama Allah. Dengan demikian ANO dimaksudkan dapat mengambil hikmah serta tauladan terhadap sikap, perilaku dan semangat perjuangan para sahabat Nabi yang mendapat predikat Ansor tersebut. Gerakan ANO (yang kelak disebut GP Ansor) harus senantiasa mengacu pada nilai-nilai dasar Sahabat Ansor, yakni sebagi penolong, pejuang dan bahkan pelopor dalam menyiarkan, menegakkan dan membentengi ajaran Islam. Inilah komitmen awal yang harus dipegang teguh setiap anggota ANO (GP Ansor). Meski ANO dinyatakan sebagai bagian dari NU, secara formal organisatoris belum tercantum dalam struktur organisasi NU. Hubungan ANO dengan NU saat itu masih bersifat hubungan pribadi antar tokoh. Baru pada Muktamar NU ke-9 di Banyuwangi, tepatnya pada tanggal 10 Muharram $1353 \mathrm{H}$ atau 24 April 1934, ANO diterima dan disahkan sebagai bagian (departemen) pemuda NU dengan pengurus antara lain: Ketua H.M. Thohir Bakri; Wakil Ketua Abdullah Oebayd; Sekretaris H. Achmad Barawi dan Abdus Salam (tanggal 24 April itulah yang kemudian dikenal sebagai tanggal kelahiran Gerakan Pemuda Ansor). 
Dalam kegiatan pengabdian kepada masyarakat Dosen UMN ini menyasar pada GP Ansor Kabupaten Tangerang karena lokasi kampus UMN memang berada di kawasan Tangerang yang termasuk alam wilayah Kabupaten Tangerang Banten.

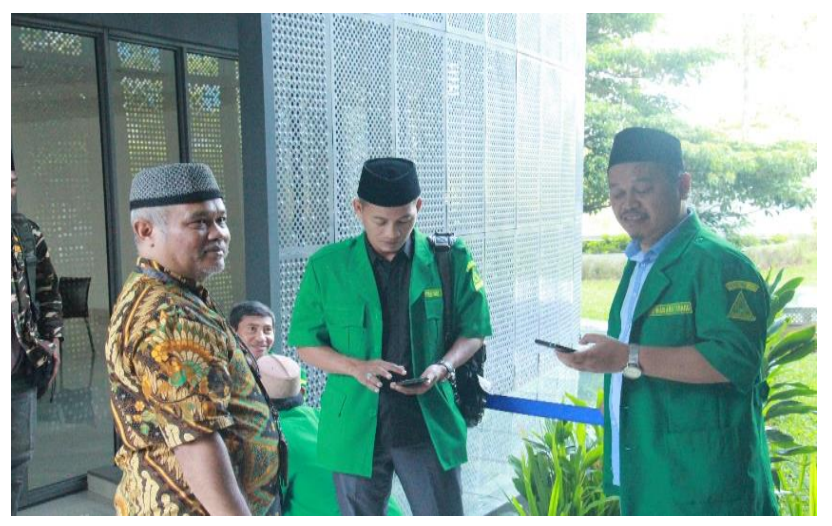

Mitra dalam pengabdian ini memiliki masalah sebagai berrikut, dan diberikan solusi oleh pengabdi tertuang dalam table di bawah ini :

\begin{tabular}{|c|c|c|}
\hline MASALAH & $\begin{array}{l}\text { URAIAN } \\
\text { MASALAH }\end{array}$ & $\begin{array}{l}\text { SOLUSI YANG } \\
\text { DITAWARKAN }\end{array}$ \\
\hline $\begin{array}{l}\text { Banyak kegiatan } \\
\text { tapi miskin } \\
\text { publikasi }\end{array}$ & $\begin{array}{l}\text { Pubikasi } \\
\text { kurang } \\
\text { mengenai } \\
\text { sasaran karena } \\
\text { keterbatasan } \\
\text { SDM yang } \\
\text { mengetahui } \\
\text { bagaimana } \\
\text { melakukan } \\
\text { publikasi yang } \\
\text { efektif }\end{array}$ & $\begin{array}{l}\text { Memberi } \\
\text { pelatihan dan } \\
\text { pendampingan } \\
\text { pesertadalam } \\
\text { membuat } \\
\text { publikasi }\end{array}$ \\
\hline $\begin{array}{l}\text { Banyak SDM tetapi } \\
\text { tidak memiliki } \\
\text { kemampuan untuk } \\
\text { publikasi }\end{array}$ & $\begin{array}{l}\text { SDM GP Ansor } \\
\text { tidak memiliki } \\
\text { pengetahuan } \\
\text { dan } \\
\text { ketrampilan } \\
\text { dalam } \\
\text { membuat } \\
\text { publikasi }\end{array}$ & $\begin{array}{l}\text { Memberi } \\
\text { pelatihan dan } \\
\text { pendampingan } \\
\text { agar SDM GP } \\
\text { Ansor bisa } \\
\text { menguasai } \\
\text { kemampuan } \\
\text { mengedit dan }\end{array}$ \\
\hline
\end{tabular}

\begin{tabular}{|c|c|c|}
\hline & & $\begin{array}{l}\text { membuat } \\
\text { video } \\
\text { menggunakan } \\
\text { HP }\end{array}$ \\
\hline $\begin{array}{l}\text { Punya peralatan } \\
\text { canggih tapi tidak } \\
\text { tahu } \\
\text { memanfaatkannya } \\
\text { dalam publikasi }\end{array}$ & $\begin{array}{l}\text { Mereka } \\
\text { memiliki } \\
\text { peralatan } \\
\text { seperti kamera } \\
\text { dan } \\
\text { handphone } \\
\text { smartphone } \\
\text { tetapi tidak } \\
\text { bisa } \\
\text { memanfaatkan } \\
\text { secara } \\
\text { maksimal } \\
\text { untuk publikasi }\end{array}$ & $\begin{array}{l}\text { Memberi } \\
\text { pelatihan } \\
\text { praktis } \\
\text { membuat } \\
\text { video kegiatan } \\
\text { menggunakan } \\
\text { handphone }\end{array}$ \\
\hline $\begin{array}{l}\text { Membuat video } \\
\text { menggunakan } \\
\text { kamera video SLR } \\
\text { atau menyerahkan } \\
\text { kepada } \\
\text { videographer } \\
\text { profesional mahal }\end{array}$ & $\begin{array}{l}\text { Tidak ada } \\
\text { anggaran yang } \\
\text { cukup untuk } \\
\text { menyewa } \\
\text { videographer } \\
\text { professional } \\
\text { dan adanya } \\
\text { keterbatasan } \\
\text { alat kamera } \\
\text { video yang } \\
\text { dimiliki }\end{array}$ & $\begin{array}{l}\text { Mengajarkan } \\
\text { dan } \\
\text { mempraktikan } \\
\text { langsung } \\
\text { pembuatan } \\
\text { video } \\
\text { menggunakan } \\
\text { kamera } \\
\text { handphone } \\
\text { yang murah } \\
\text { dan praktis }\end{array}$ \\
\hline $\begin{array}{l}\text { Memiliki } \\
\text { handphone dan } \\
\text { serring merekam } \\
\text { kegiatan } \\
\text { menggunakan } \\
\text { kamera video tapi } \\
\text { tidak mengetahui } \\
\text { apikasi }\end{array}$ & $\begin{array}{l}\text { Aplikasi yang } \\
\text { digunakan di } \\
\text { handphone } \\
\text { banyak yang } \\
\text { terkait dengan } \\
\text { perekaman } \\
\text { video }\end{array}$ & $\begin{array}{l}\text { Menjelaskan } \\
\text { dan } \\
\text { membimbing } \\
\text { peserta } \\
\text { memanfaatkan } \\
\text { aplikasi } \\
\text { videoshow dan } \\
\text { Canva untuk } \\
\text { membuat } \\
\text { video praktis }\end{array}$ \\
\hline
\end{tabular}

Berdasarkan masalah dan solusi yang ditawarkan maka pengabdi memberikan pelatihan dan pendampingan bagaimana membuat dan mengedit video menggunakan aplikasi praktis seperti Canva dan Videoshow bagi anggota GP Ansor Kabuaten Tangerang. Tujuannya adalah agar 
terjadi peningkatan kemampuan mitra dalam membuat publikasi kegiatan-kegiatan GP Ansor . Output atau luaran disamping bisa meningkatkan kemampuan GP Ansor maka hasilnya bisa dibuat tuisan dan dikirimkan ke jurnal dan dipubikasi ke media massa.

B. Tinjauan Pustaka/Kerangka berpikir

Merekam dan mengedit video mengggunakan handphone sebenarnya mudah asal kita bisa mengikuti arahan ini. Sebelum merekam video bersihkan lensa kamera Handphone. Jika lensa sudah cukup bersih, langkah selanjutnya adalah melakukan pengaturan manual di menu Settings pada Video di smartphone Android. Jadi, sebelum merekam pastikan kita memilih kualitas video seperti apa yang kita inginkan.

Disarankan pilih kualitas video dengan angka paling tinggi yakni 1080p. Di beberapa smartphone Android premium, kita bahkan bisa memilih kualitas video berdasarkan frame per second alias fps-nya. Nah, jika kebetulan smartphone Android mengusung pengaturan tersebut maka cobalah memilih kualitas video pada angka $1080 \mathrm{p}$ at $30 \mathrm{fps}$. Angka ini bakal membuat video yang kita rekam hasilnya lebih mulus dan jernih, artinya tak jauh beda objek yang akan direkam dengan objek setelah direkam atau setelah jadi video. Matikan penggunaan EIS karena pengaturan Electrical Image Stabilization bisa membuat kualitas video malah turun. Meski pada umumnya EIS ini membantu secara otomatis agar video yang kita rekam hasilnya lebih bagus, pengaturan ini justru bikin kualitas video malah jelek.

Untuk menghindari guncangan perlu pakai tripod. Minusnya merekam pakai kamera smartphone Android itu adalah guncangan lebih sering terjadi, karena tangan si perekam yang bergetar saat merekam. Guncangan sekecil apapun nyatanya dapat memengaruhi hasil rekaman lho. Untuk itulah, sebisa mungkin gunakan tripod atau stabilizer saat merekam dengan kamera smartphone Android. Menggunakan perangkat ini bisa meminimalisir guncangan dan juga bisa membantu ketika hendak bikin video sendiri tanpa bantuan orang lain seperti vlog misalnya. Merekam dengan kamera smartphone Android memang tidak bisa sembarangan. Kita hanya diperkenankan memosisikan kamera smartphone Android secara horisontal. Hal ini perlu dilakukan agar hasil rekaman lebih estetis dan mudah ketika mau diupload ke channel YouTube atau sekadar dibagi di Instagram. Merekam dalam posisi horisontal juga bisa memudahkan kita saat akan mengedit, karena tidak ada sisa border berwarna hitam yang bisa bikin tampilan video jadi kurang menarik.

Setelah itu gunakanlah aplikasi menngedit video yang praktis seperti menggunakan Kinemaster, Viva video atau Videoshow. Di Android sangat banyak aplikasi yang sesuai , gunakan yang praktis dan sesuai dengan kemampuan kita. Dalam program pengabdian ini pengabdi menggunakan aplikasi Videoshow. Untuk lebih jelasnya bagaimana mengedit video biisa mengklik tautan ini.

https://www.youtube.com/watch?v=nQam1Z_Q$\underline{E Q}$

\section{METODOLOGI}

Dalam kegiatan pengabdian ini metode yang digunakan adalah sebagai berikut:

1. Pertama-tama mencari tahu dan mengidentifikasi masalah dan kebutuhan mitra dalam hal ini adalah GP Ansor Kabupaten Tangerang yang merasa kesulitan dalam melakukan publikasi

2. Memberi pelatihan dan pendampingan peserta dalam membuat publikasi

3. Memberi pelatihan dan pendampingan agar SDM GP Ansor bisa menguasai kemampuan mengedit dan membuat video menggunakan HP

4. Mengajarkan dan mempraktikan langsung pembuatan video menggunakan kamera handphone yang murah dan praktis dengan menggunakan apllikasi Android Canva dan Videoshow

\section{PELAKSANAAN KEGIATAN DAN PEMBAHASAN}

PROSIDING PKM-CSR 2019 


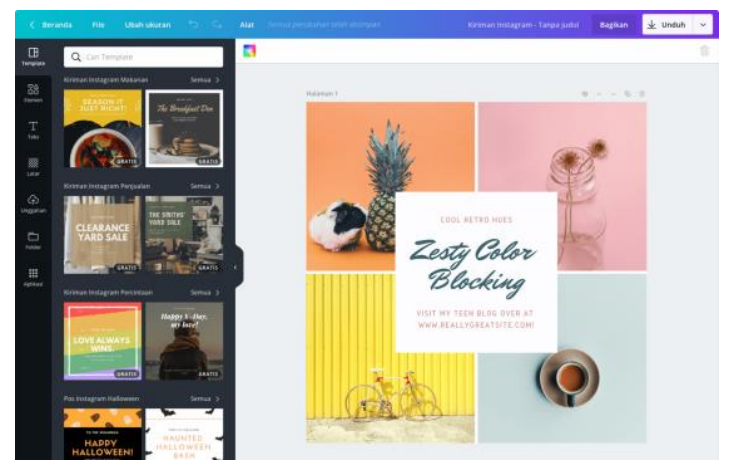

Kegiatan pelatihan videografi unuk publikasi ini dilakukan pada 14 Juli 2019 dengan peserta dari GP Ansor Kabupaten Tangerang. Acara dibuka dengan presentasi pengabdi tentang pentingnya publikasi kegiatan organisasi, kemudian diajarkan bagaimana GP Ansor Kabupaten Tangerang mengisntal aplikasi yang sesuai untuk publikasi. Ada dua aplikasi yang diajarkan yaitu Canva dan Aplikasi Videoshow.

Aplikasi praktis ini sangat efektif dalam mengembangkan kemampuan peserta dalam merekam video dan mengeditnya secara cepat dan professional, meskipun tidak seribet dan sesulit apabila menggunakan kamera video SLR. Setelah mengajarkan kemudian peserta melakuukan praktek merekam video dan melakukan editing langsung di handphone mereka. Kemudian hasilnya bisa dikirimkan ke Instagram peserta. Dan dikirimkan ke Youtube.

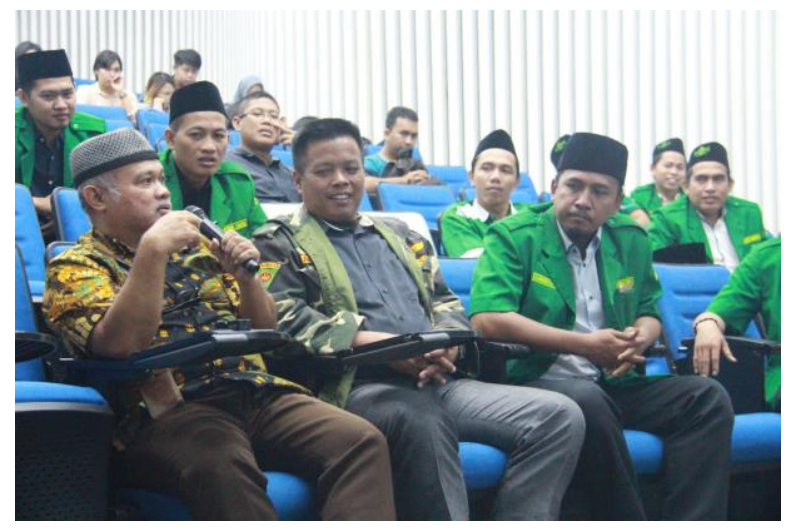

KESIMPULAN DAN SARAN
Kesimpulan yang bisa diraih dalam program pengabdian kepada masyarakat ini adalah tidak semua organisasi termasuk di dalamnya GP Ansor memiliki kemampuan publikasi yang mumpuni dan bagus, tetapi mereka masih miskin informasi dan pengetahuan untuk membbuat video yang lebih professional. Di sinilah peran dan tugas ilmuwan serta akademisi mengisi kelemahan dan kekurangan oorganisasi dalam segi publikasi lewat pelatihan videografi.

Selain itu, sebenarnya aplikasi praktis di Android terkait pengeditan dan pembuatan video sangat banyak dan menawarkan banyak kemudahan, tetapi apabila kita tidak memahaminya maka percuma saja kamera kita yang cangggih dan mahal itu tidak berguna, karena kurang memiliki informasi. Lewat pelatihan dan pendampingan ini, peserta bisa memanfaatkan dan menguasai teknologi perekaman dan pengeditan video secara praktis bahkan secara mudah lewat smartphone yang dimilikinya.

Saran yang bisa disampaikan pengabdi adalah, perlunya mengasah kemampuan merekam video dan mengeditnya agar publikasi kegiatan organisasi menjadi lebih efektif. Organisasi yang baik adalah organisasi yang bisa melakukan kegiatan nyata yang bermanfaat bagi masyarakat sekaligus bisa mengangkat citra organisasi lewat publikasi yang dilakukannya. Untuk GP Ansor Kabupaten Tangerang, tentunya tidak berhenti di sinni, ke depan bisa ditingkatkan kemampuan peserta untuk membuat publikasi yang lebih professional menggunakan kamera SLR.

DAFTAR BACAAN

https://www.idntimes.com/tech/trend/indr a/cara-bikin-video-bagus-pakaismartphone/full https://www.idntimes.com/tech/trend/aida -fajriyatin-formaningrum/aplikasi-editingvideo-di-android-c1c2 https://www.youtube.com/watch?v=nQam1 $\underline{Q} Q-E Q$

https://id.wikipedia.org/wiki/Gerakan Pem uda Ansor

PROSIDING PKM-CSR 2019 